Research Article

\title{
A Study to Assess the Effectiveness of Safe Delivery Application for Pre-Service Nursing Students in a Selected College of Nursing of New Delhi
}

\author{
Sana Usmani', Manju Chhugani ${ }^{2}$, Mikki Khan $^{3}$ \\ ${ }^{1}$ M.Sc. Nursing, ${ }^{2}$ Dean, ${ }^{3}$ Tutor, Rufaida College of Nursing, Jamia Hamdard, New Delhi, India. \\ DOI: https://doi.org/10.24321/2455.9318.201928
}

I $\quad \begin{array}{lllll}\mathbf{N} & \mathbf{F} & \mathbf{O}\end{array}$

Corresponding Author:

Sana Usmani, Rufaida College of Nursing, Jamia

Hamdard, New Delhi, India.

E-mail Id:

sanausmani02@gmail.com

Orcid Id:

https://orcid.org/0000-0003-2954-4389

How to cite this article:

Usmani S, Chhugani M, Khan M. A Study to Assess the Effectiveness of Safe Delivery Application for Pre-Service Nursing Students in a Selected College of Nursing of New Delhi. Int J Nurs Midwif Res 2019; 6(4): 22-27.

Date of Submission: 2019-07-29

Date of Acceptance: 2020-02-18

\section{$\begin{array}{lllllllllllll}\mathbf{A} & \mathbf{B} & \mathbf{S} & \mathbf{T} & \mathbf{R} & \mathbf{A} & \mathbf{C} & \mathbf{T}\end{array}$}

Introduction: The Safe Delivery Application is a mHealth tool that can be used for health workers who manage normal and complicated deliveries in the peripheral areas. The application has clinical instruction films on key obstetric procedures which can help the health workers translate their learnt skills into practice.

Objective: The main objectives of the study were to assess the effectiveness of safe delivery application on its utilization in pre-service training update knowledge on $\mathrm{MNH}$ practices among nursing students.

Methodology: The research design for this study was a pre-experimental design, "one group pre-test post-test only design, 100 nursing students by using total enumeration sampling technique. In the present study, base measures were knowledge regarding active management of third stage labour, postpartum hemorrhage, neonatal resuscitation by using safe delivery application to nursing students of Rufaida College of Nursing New Delhi.

Result: The data obtained was analyzed by using the descriptive and inferential statistics. The findings reveal that there was deficit in knowledge of the nursing students (mean=17.12, S.D=4.18), but after utilization of safe delivery application the post-test scores (mean=42.26, $S D=6.60$ ) in terms of knowledge was significantly higher than the pre-test scores. This indicates that the safe delivery application on Active management of third stage labour, Postpartum Hemorrhage, Neonatal Resuscitation was effective in improving the knowledge of nursing students.

Conclusion: The findings of the study indicated that safe delivery application was found to be effective in improving the knowledge of nursing students on active management of third stage labour, postpartum hemorrhage, neonatal resuscitation.

Keywords: Nursing Students, Active Management of Third Stage Labour, Postpartum Hemorrhage, Neonatal Resuscitation 


\section{Introduction}

Childbirth is an intense event and strong emotions both positive and negative can be brought to the surface. Labour is a process, where women give birth to the child. The most wonderful moment in women's life is during labour, as most women and their families experience greatest excitement during labour. The anticipated period of uncertainty, anxiety and fear, ends with beautiful birth of the baby. Clearly, the support and care they receive during this time is critical. Childbirth is a divine process and women should be supported during labor. ${ }^{1}$ Thus the overall aim of caring for women during labour and birth is to engender, a positive experience for the women and her family, while maintaining their health, preventing complications and responding to emergencies promptly. ${ }^{2}$ Global observation shows that more than 50 million women suffer from a serious pregnancy related illness or disability. At least 1.2 million newborn infants die due to inadequate and unskilled care that they receive during delivery and it is estimated that every year more than 585,000 women die worldwide from pregnancy and childbirth related complications. ${ }^{3}$ Recent epidemiological evidence from a range of developing countries suggests that skilled care during child birth may help to prevent maternal deaths. ${ }^{4}$ Steps to minimize hemorrhagic complications include identification of high risk patients through complete history, vigilant management of third stage of labour and having uterotonic medications readily available in the delivery room. The common errors such as not treating anemia in pregnancy, not practicing Active Management of Third Stage of Labour (AMTSL), delay in recognition, substandard care and lack of skills should be identified and corrected. ${ }^{5}$ Recently in June 2018 a news article was published on significant impact of the safe delivery app. Midwives in Northern Ghana have increased their knowledge 40 percent after using the Safe Delivery App for just three months. That is just one of the impressive results revealed at a stakeholder convening on the Safe Delivery App in Ghana. ${ }^{6}$

\section{Materials and Methods}

The quantitative descriptive research approach was adopted for the study with Pre-Experimental Research design, one group pre-test post-test design. The duration data were collected from $1^{\text {st }}$ October, 2018 to $30^{\text {th }}$ October, 2018 of the study was one month. Inclusion criteria included those Students who are having smart phone, Students of $4^{\text {th }}$ year of B.Sc. (Hons.) Nursing, $3^{\text {rd }}$ year Diploma-General Nursing and Midwifery (DGNM), $1^{\text {st }}$ year Post Basic B.Sc. nursing and $1^{\text {st }}$ year M.Sc. Nursing students who were available at the time of the study. Research variables are- Independent Variable as Safe Delivery Application (Smart Phone Application) Dependent Variable as knowledge of nursing students on Active Management of Third Stage of Labour (AMTSL), Post-
Partum Hemorrhage (PPH) and Neonatal Resuscitation. A total of 100 nursing students in a selected college of nursing New Delhi by total enumeration sampling technique were included in the study. The tools used were structured knowledge questionnaire and structured opinionnaire. Reliability of the structured knowledge questionnaire was computed by KR-20 and was found to be 0.91 . Reliability of structured opinionnaire was worked out by Cronbach's Alpha and was found to be 0.75 . Thus, tool was found to be reliable. Those who met the inclusion criteria of having smart phone participated in the study. On day 1, the pre-test was conducted to assess the existing knowledge of nursing students on AMTSL, PPH and neonatal resuscitation and then nursing students installed the safe delivery application on their phones. On day 30, post-test for assessing the effectiveness of safe delivery application regarding AMTSL, $\mathrm{PPH}$ and neonatal resuscitation was conducted through the structured knowledge questionnaire and opinionnaire of safe delivery application use by nursing students.

The study protocol was approved by Jamia Hamdard Institutional Review Board for Ethical Clearance and written informed consent was obtained from the subjects.

\section{Result \\ Table I.Frequency and percentage distribution of nursing students by their demographic characteristics}

$(n=100)$

\begin{tabular}{|c|c|c|c|}
\hline $\begin{array}{c}\text { S. } \\
\text { No. }\end{array}$ & Characteristics & Frequency & $\begin{array}{c}\text { Percentage } \\
\%\end{array}$ \\
\hline \multirow{4}{*}{1.} & Age in years & & \\
\cline { 2 - 4 } & $19-21$ & 80 & 80 \\
\cline { 2 - 4 } & $22-24$ & 18 & 18 \\
\cline { 2 - 4 } & $25-27$ & 1 & 1 \\
\hline \multirow{4}{*}{2.} & $>27$ & 1 & 1 \\
\cline { 2 - 4 } & Course & & \\
\cline { 2 - 4 } & Dost Basic B.Sc. & 29 & 29 \\
\cline { 2 - 4 } & nursing & 19 & 19 \\
\cline { 2 - 4 } & B.Sc. (Hons.) nursing & 47 & 47 \\
\cline { 2 - 4 } & M.Sc. nursing & 5 & 5 \\
\hline
\end{tabular}

Out of total 100 nursing students, more than half nursing student i.e. 80 (80\%) were in the age group of $19-21$ years and $18(18 \%)$ were in age group of $22-24$ years and $1(1 \%)$ each were in the age group of 25-27 years and $>27$ years (Figure 2). With regard to their professional qualification of the subjects, 29 (29\%) were of DGNM $3^{\text {rd }}$ year, followed by 47 (47\%) of B.Sc. (hons) Nursing $4^{\text {th }}$ year, $19 \%$ of Post basic B.Sc nursing $1^{\text {st }}$ year and $5(5 \%)$ of M.Sc. Nursing $1^{\text {st }}$ year. 
Table 2(a).Range of score, mean, median and standard deviation of pre-test and post-test knowledge scores of nursing students regarding active management of third stage labour, postpartum hemorrhage and neonatal resuscitation

\begin{tabular}{|c|c|c|c|c|}
\hline Knowledge Test & Range of obtained score & Mean & Median & Standard Deviation \\
\hline Pre-test & $0-20$ & 17.12 & 17 & 4.18 \\
\hline Post-test & $41-60$ & 42.26 & 42 & 6.60 \\
\hline
\end{tabular}

Maximum Scores $=60$ in post-test

Table 2(b).Frequency and percentage distribution of nursing students by the level of knowledge based on their pre-test and post-test knowledge scores

$(n=100)$

\begin{tabular}{|c|c|c|c|c|c|}
\hline \multirow{2}{*}{ Grading } & \multirow{2}{*}{ Scores } & \multicolumn{2}{|c|}{ Pre-test knowledge score } & \multicolumn{2}{c|}{ Post-test knowledge score } \\
\cline { 3 - 6 } & & Frequency & Percentage \% & Frequency & Percentage \% \\
\hline Poor & $0-20$ & 77 & 77 & 0 & 0 \\
\hline Average & $21-40$ & 23 & 23 & 60 & 60 \\
\hline Good & $41-60$ & 0 & 0 & 40 & 40 \\
\hline
\end{tabular}

Maximum score $=60$.

Table 3.Mean, standard deviation and ' $z$ ' value of pre and post-test knowledge scores of nursing students

\begin{tabular}{|c|c|c|c|c|}
\hline Test & Mean & Standard deviation & ' $z$ ' value & p-value \\
\hline Pre-test knowledge score & 17.12 & 4.18 & \multirow{2}{*}{32.16} & 0 \\
\hline Post-test knowledge score & 42.26 & 6.60 & & \\
\hline
\end{tabular}

$* * p<0.05$ table value $z=1.96(p=0)$ at $p<0.05(98)$.

The data presented in Table 2(a), reveals that the mean posttest knowledge scores was (42.26). This indicates the gain in knowledge by the nursing students. Standard deviation of pre-test and post-test knowledge scores was 4.18 and 6.60 respectively. Difference in the standard deviation was slight but direction indicates the group was more homogenous in the post-test. The table- 2 indicates that most of the nursing students achieved a higher post-test knowledge score than pre-test knowledge score, suggesting the knowledge gain by the nursing students.

The data presented in Table 2(b), reveals after utilization of safe delivery application on active management of third stage labour, postpartum hemorrhage and neonatal resuscitation by nursing students, it showed that the majority of nursing students, 40 (40\%) had good knowledge followed by 60 ( $60 \%$ ) having average knowledge and there was no student who had poor knowledge on three topics mentioned above.

Comparison between Pre-test and Post-test Knowledge Score before and after Utilization of Safe Delivery Application regarding Active Management of Third Stage Labour, Postpartum Hemorrhage and Neonatal Resuscitation among Nursing Students

Data presented in Table 3, shows that computed ' $z$ ' value of all the areas and the overall test to assess knowledge regarding the effects of safe delivery application on active management of third stage labour, postpartum hemorrhage and neonatal resuscitation $z$ value is greater than the table value $z(98)=1.96$ at 0.05 level of significance. Hence, the null hypothesis is rejected and thus it is concluded that the use of safe delivery application has been effective in increasing the knowledge of nursing students regarding active management of third stage labour, postpartum hemorrhage and neonatal resuscitation.

Association between Post-test Knowledge Scores of Nursing Students with Selected Demographic Variables

Table 4 (a).Association between post-test knowledge level of nursing students and selected demographic variables

\begin{tabular}{|c|c|c|c|c|c|}
\hline \multirow{2}{*}{$\begin{array}{c}\text { Age } \\
\text { in } \\
\text { years }\end{array}$} & \multicolumn{2}{|c|}{$\begin{array}{c}\text { Post-test } \\
\text { knowledge level }\end{array}$} & $\begin{array}{c}\text { Chi Square } \\
(\chi 2)\end{array}$ & df & ' $p$ '-value \\
\cline { 2 - 3 } & Good & Average & & & \\
\hline $19-21$ & 47 & 33 & & & \\
\hline $22-24$ & 16 & 2 & \multirow{2}{*}{$* 6.966$} & \multirow{2}{*}{3} & \multirow{2}{*}{0.0730} \\
\hline $25-27$ & 1 & 0 & & & \\
\hline$>27$ & 1 & 0 & & & \\
\hline$\chi 2(3)=6.966, p>0.05$. &
\end{tabular}


The data in Table 4(a), shows that the obtained chi-square of 6.966 is smaller than the table value [at df (3) 7.82] at 0.05 level of significance. Hence the hypothesis $\left(H_{1}\right)$ was rejected and concluded that there is no significant association between age and the post-test knowledge score of nursing students.

The data in Table 4(b), shows that the obtained chi-square of 50.995 is greater than the table value of [at df (9) 7.82] at 0.05 level of significance. Hence the hypothesis $\left(\mathrm{H}_{01}\right)$ was accepted and concluded that there is significant association between educational qualification and the post-test level of knowledge $(\mathrm{P}<0.05)$.

Therefore, findings suggested that more the educational qualification higher the gain in knowledge level of nursing students.

Table 4(b).Association between post-test knowledge level of nursing students and selected demographic variables

\begin{tabular}{|c|c|c|c|c|c|}
\hline \multirow{2}{*}{ Professional qualification } & \multicolumn{2}{|c|}{ Post-test knowledge level } & \multirow{2}{*}{$\begin{array}{c}\text { Chi Square } \\
(x 2)\end{array}$} & \multirow{2}{*}{ Df } & \multirow{2}{*}{ 'p'-value } \\
\hline & Good & Average & & & \\
\hline DGNM $3^{\text {rd }}$ year & 2 & 27 & \multirow{4}{*}{ *50.995 } & \multirow{4}{*}{3} & \multirow{4}{*}{0.0000} \\
\hline B.Sc. (Hons) Nursing $4^{\text {th }}$ year & 38 & 8 & & & \\
\hline Post Basic B.Sc. Nursing $1^{\text {st }}$ year & 15 & 4 & & & \\
\hline M.Sc. Nursing $1^{\text {st }}$ year & 5 & 0 & & & \\
\hline
\end{tabular}

$\chi 2(3)=50.995, p>0.05$.

\section{Opinion of Nursing Students on the Use of Safe Delivery Application}

Table 5(a).Frequency and percentage of the responses on the opinion of nursing students regarding use of safe delivery application

$(n=100)$

\begin{tabular}{|c|c|c|c|c|c|c|c|c|c|c|c|}
\hline $\begin{array}{l}\text { S. } \\
\text { No. }\end{array}$ & Statements & $\begin{array}{r}\text { Stro } \\
\text { ag }\end{array}$ & & & & Unc & tain & Dis & ree & & \\
\hline & $\begin{array}{l}\text { Safe delivery App has no interruptions while } \\
\text { using in offline mode }\end{array}$ & 71 & 71 & 29 & 29 & 0 & 0 & 0 & 0 & 0 & 0 \\
\hline & Simple and easy to understand & 22 & 22 & 63 & 63 & 15 & 15 & 0 & 0 & 0 & 0 \\
\hline & Usage of easy terminology & 65 & 65 & 26 & 26 & 8 & 8 & 1 & 1 & 0 & 0 \\
\hline & Provided adequate information & 34 & 34 & 59 & 59 & 7 & 7 & 0 & 0 & 0 & 0 \\
\hline & Arranged in the sequence & 30 & 30 & 53 & 53 & 12 & 12 & 5 & 5 & 0 & 0 \\
\hline & Font is legible & 65 & 65 & 23 & 23 & 10 & 10 & 0 & 0 & 0 & 0 \\
\hline & Content up to date & 64 & 64 & 28 & 28 & 8 & 8 & 0 & 0 & 0 & 0 \\
\hline & Content is clear. & 95 & 95 & 5 & 5 & 0 & 0 & 0 & 0 & 0 & 0 \\
\hline & Content coverage is relevant & 55 & 55 & 33 & 33 & 11 & 11 & 1 & 1 & 0 & 0 \\
\hline & Content is precise & 40 & 40 & 60 & 60 & 0 & 0 & 0 & 0 & 0 & 0 \\
\hline & $\begin{array}{l}\text { Safe delivery App has videos relevant to } \\
\text { content }\end{array}$ & 41 & 41 & 59 & 49 & 0 & 0 & 0 & 0 & 0 & 0 \\
\hline & Videos can be played easily & 82 & 82 & 18 & 18 & 0 & 0 & 0 & 0 & 0 & 0 \\
\hline & Videos sound is clear & 24 & 24 & 76 & 76 & 0 & 0 & 0 & 0 & 0 & 0 \\
\hline & The app has eye friendly colors & 70 & 70 & 30 & 30 & 0 & 0 & 0 & 0 & 0 & 0 \\
\hline & $\begin{array}{c}\text { Safe Delivery App is more effective than class } \\
\text { room teaching. }\end{array}$ & 12 & 12 & 10 & 10 & 35 & 35 & 33 & 33 & 10 & 10 \\
\hline & $\begin{array}{l}\text { Safe delivery App can be really used while } \\
\text { preparing for exams }\end{array}$ & 11 & 11 & 87 & 87 & 2 & 2 & 0 & 0 & 0 & 0 \\
\hline & The videos are useful for clinical procedures & 65 & 65 & 25 & 25 & 10 & 10 & 0 & 0 & 0 & 0 \\
\hline
\end{tabular}


Data in Table 5(a), shows the responses of the nursing students on the statements of useing safe delivery application. The responses are in five opinions as strongly agree, agree, uncertain, disagree and strongly disagree.

- Majority i.e. $71 \%$ of the nursing students strongly agree that safe delivery application had no interruptions while using in offline mode and $29 \%$ agree to this statement.

- Majority i.e. $63 \%$ of the nursing students agree that safe delivery application had simple and easy to understand language and $22 \%$ strongly agree to this statement.

- Majority i.e. $65 \%$ of the nursing students strongly agree that safe delivery application had used easy terminology and $26 \%$ agree to this statement.

- As far as the safe delivery application content provided adequate information, most of the nursing students i.e. 59\% agree and 34\% strongly agree about it.

- Most of the nursing student i.e. 53\% agree that safe delivery application content is arranged in sequence, $30 \%$ strongly agree with it, $12 \%$ were uncertain and $5 \%$ disagreed about it.

- $65 \%$ nursing students strongly agree that safe delivery application content font was legible, $23 \%$ agree and $10 \%$ are uncertain.

- Majority i.e. $64 \%$ of the nursing students strongly agree that safe delivery application content was up to date, $33 \%$ agree to this statement, $11 \%$ were uncertain and $1 \%$ disagreed about it.

- Most of the nursing student i.e. 95\% agree that safe delivery application content was clear and $1 \%$ agree to this statement.

- Majority of the nursing students i.e. 59\% agree that safe delivery application had videos relevant to content and $41 \%$ strongly agree to this statement

- $82 \%$ of the nursing students strongly agree that safe delivery application videos can be played easily and $18 \%$ agree about it.

- $76 \%$ of the nursing student agree that safe delivery application videos' sound is clear and $24 \%$ strongly agree about it.

- Majority of the nursing students i.e. $70 \%$ strongly agree about the safe delivery application has eye friendly colors/soothing and $30 \%$ agree to this statement.

- For the effectiveness/acceptability of the safe delivery application being more effective than classroom teaching, most of the nursing students i.e. 35\% were uncertain about it, 33\% disagreed and 10\% strongly disagreed to this statement, only $12 \%$ strongly agreed and $10 \%$ agreed to it.

- $\quad 87 \%$ of the nursing students agree and $11 \%$ strongly agree that safe delivery application can be easily used while preparing for the exams, while only $2 \%$ were uncertain about this statement.
- Majority of the nursing students i.e. 65\% strongly agree and $25 \%$ agree that safe delivery application videos are useful for clinical procedures, and only $10 \%$ are uncertain about it.

\section{Discussion}

The study revealed significant positive difference between pre- and post-test knowledge scores of nursing students regarding active management of third stage labour, postpartum hemorrhage and neonatal resuscitation by using safe delivery application. As per the study it was evident that use of safe delivery application in pre-service nursing education was an effective strategy to enhance knowledge of nursing students. A similar project done by maternity foundation conducted in Ethiopia on Safe Delivery App with total sample consisting of 107 users of the safe delivery application, data collected through interviews, questionnaires and follow-up calls, reported similar findings. The safe delivery application users in the sample of Ethiopia study were mainly female (79\%), with a midwifery diploma degree corresponding to 2 years' education (97\%). The mean baseline score of skilled birth attendants on the pre-test was $36 \%$ and the mean midterm score was $56 \%$, with a mean improvement $10 \%$-points. ${ }^{7}$

\section{Recommendation}

On the basis of the findings of the study following recommendations have been made: $A$ replication of present study can be conducted with a larger population. A similar study can be conducted in different colleges of nursing. A similar study can be conducted on different topics of the safe delivery application such as prolonged labour, maternal sepsis and newborn management. A similar study can be conducted with obstetrical and gynecological department staff nurses and with community health nurses.

\section{Conclusion}

The descriptive and inferential analysis and interpretation of data on five sections collected from 100 nursing students from Rufaida College of Nursing, Jamia Hamdard, New Delhi, concluded that the safe delivery application on AMTSL, PPH and neonatal resuscitation was effective in enhancing their knowledge.

\section{Conflict of Interest: None}

\section{References}

1. Basavanthappa BT. Textbook of Midwifery and Reproductive Health Nursing. $1^{\text {st }}$ ed. Jaypee Brother Medical Publishers (P) Ltd., New Delhi. 2006; 153. Available from: https://www.abebooks.com/booksearch/kw/textbook-of-midwifery-reproductive-healthnursing-b-t-basavanthappa/.

2. Susan C. Family-centered maternity \& new born 
care. Public health agency of Canada. Available from: http://205.193.86.76/dca-dea/publication and fcmc 05-eng.php.

3. Michael GA. Skilled Birth attendant competence and facility readiness for managing obstetric emergencies in Eritrea. Journal of Eritrean medical association 2006; 1(1): 24-27. Available from: https://www.ajol.info// index.php/jema/article/view/52641 [Google Scholar].

4. Mia M, Ann S. Saving women's lives, improving newborn health. Skilled care during childbirth information booklet. Available from: http://www.safemotherhood. org.website.

5. Kominiarek MA, Kilpatrick SJ. Postpartum hemorrhage: a recurring pregnancy complication. Semin Perinatol 2007; 31(3): 159-166. Available from: https:// www.sciencedirect.com/science/article/abs/pii/ S0146000507000328?via\%3Dihub [PubMed/ Google Scholar].

6. Maternity foundation. Significant impact of the safe delivery app in Ghana. Available from: https://www. maternity.dk/significant-impact-of-the-safe-deliveryapp-in-ghana.

7. Maternity Foundation, safe delivery app data report, Ethiopia Country Case 2016-2017. Available from: https://www.maternity.dk>D. 